Research Article

\title{
Drug prescribing patterns in patients visiting the emergency medicine department at a tertiary care teaching hospital: a prospective study
}

\author{
Krishna Pandey*, Irfan A. Khan
}

Department of Pharmacology, Teerthanker Mahaveer Medical College and Research Centre, Moradabad, India

Received: 1 December 2015

Revised: 2 December 2015

Accepted: 7 January 2016

*Correspondence to:

Dr. Krishna Pandey,

Email:krishnapandey0507@hotmail.com

Copyright: ( the author(s), publisher and licensee Medip Academy. This is an open-access article distributed under the terms of the Creative Commons

Attribution Non-Commercial License, which permits unrestricted noncommercial use, distribution, and reproduction in any medium, provided the original work is properly cited.

\begin{abstract}
Background: Drug utilization studies seek to monitor, evaluate and suggest modifications in the prescribing practices with the aim of making the medical care rational and cost effective. A study of prescription patterns is an important tool to determine rational drug therapy and maximize utilization of resources.

Methods: This study was a prospective, cross sectional \& observative study of patients $(\mathrm{N}=250)$ who attended the emergency medicine department of TMMC \& RC, Moradabad, U.P., India.

Results: A total of 250 patients received 2004 drugs with the mean of $8.016 \pm 1.935 /$ patient. The average stay of patients in the emergency medicine department was 3.025 \pm 1.010 days. Most common disorder was of cardiovascular system $(\mathrm{N}=65,26 \%)$. Pantoperazole $(\mathrm{N}=180)$ was most common drug prescribed followed by ondansetron $(\mathrm{N}=148)$. Conclusions: Maximum number of patient attended in emergency medicine department was of cardiovascular disorder followed by respiratory disorder. pantoperazole and ondansetron were the most commonly prescribed drugs. Polypharmacy was prevalent. The result of our study highlights the importance of strategies that have to be implemented to optimize medication use in emergency medicine department.
\end{abstract}

Keywords: Drug, Emergency medicine, Cardiovascular disorders, Strategies

\section{INTRODUCTION}

Medicines play an important role in health care delivery and disease prevention. The availability and affordability of good quality drugs along with their rational use is needed for effective health care. However, irrational drug use is prevalent, especially in the developing countries due to irrational prescribing, dispensing, and administration of medications. ${ }^{1}$

Drug utilization study, as defined by the WHO, is a structured process which is used to assess the quality of drug therapy by engaging in the evaluation of data on drug prescribing, dispensing and patient use in a given health care environment, against predetermined, agreed upon criteria and standards, with special emphasis on the resulting medical, social, and economic consequences. ${ }^{2}$

Appropriate drug utilization has a huge contribution to global reduction in morbidity and mortality with its consequent medical, social and economic benefits. ${ }^{3}$
Inappropriate prescribing is known all over the world as a major problem of health care delivery. ${ }^{4}$

This is more so in developing countries where health budgets are small and 30-40\% of the total health budget is spent on drugs. ${ }^{5}$

World Health Organization (WHO) has formulated a set of core drug use indicators, which measure the performance of prescribers, patients experience at health facilities and whether the health personnel can function effectively. The assessment of WHO core indicators help to improvise the prescribing pattern, identify significant problems involved in the knowledge gap of patients or caretakers understanding of instructions provided by consultants and even to minimize the cost burden on patient. The assessment of drug use indicators according to WHO guidelines on how to investigate drug use in health facilities are prescribing indicators, patient care indicators, facility indicators and complementary indicators. ${ }^{6}$ 


\section{METHODS}

\section{Study setting}

This study was conducted at the emergency medicine department and department of Pharmacology, Teerthanker Mahaveer Medical College and Research Centre (TMMC \& RC), it is 900 bedded, tertiary care teaching hospital, in Moradabad, Uttar Pradesh, India, while the ED has 22 beds. The ED is visited by approximately 10,000 patients annually.

\section{Study design and subjects}

This was a prospective, cross-sectional, and observative study of patients $(n=250)$ who attended the emergency medicine department of TMMC \& RC, Moradabad, UP, India.

\section{Study duration}

From March 2014 to February 2015.

\section{Ethical approval}

Ethical approval for the study was obtained through the medical research and ethics committee at the Teerthanker Mahaveer Medical College and Research Centre (TMMC \& RC)

Written informed consent from the patient/legal guardian was obtained prior to conduct the study.

\section{Calculation of W.H.O. prescribing indicators}

1. Average number of drugs per encounter $=$ Total number of drugs prescribed/total number of encounters surveyed.

2. Percentage of drugs prescribed by generic name $=$ (number of drugs prescribed by generic name/total number of drugs prescribed) x 100 .

3. Percentage of encounters with an antibiotic prescribed $=$ (number of patient encounters during which an antibiotic was prescribed/total number of encounters surveyed) x 100 .

4. Percentage of encounters with an injection prescribed $=$ (number of patient encounters during which an injection was prescribed/total number of encounters surveyed) x 100 .

5. Percentage of drugs prescribed from essential drugs list $=$ (number of drugs prescribed from essential drugs list / total number of prescribed drugs) x 100 .

\section{Data analysis}

Data were coded, checked for completeness and consistency. Then the data were entered and analyzed into the computer and using Microsoft excel. Indicators were calculated based on the above ratios.

Descriptive statistics were used to describe the data and results were expressed in terms of percentages and presented using tables according to the types of tool used. The results were discussed with the physicians of the study hospital.

Statistical analysis-continuous data are expressed as mean \pm S.D. No formal statistical hypothesis was tested.

For categorical variables, frequencies and percentages were reported. For continuous variables, means and standard deviations $( \pm \mathrm{SD})$ were reported.

Information recorded included age, gender, diagnosis and drugs prescribed.

\section{RESULTS}

\section{Analysis of drug utilization pattern}

In our study, prescriptions of 250 patients admitted in the emergency medicine department were collected until the patient stays in emergency department and analyzed. Among the 250 cases, 138 were males and 112 were females (Table $1 \&$ Figure 1). The mean age group of patients admitted was 47.30 \pm 16.194 years. Among the different age groups of the patients admitted, Majority 64 $(25.5 \%)$ of patients presenting to emergency medicine department were 51-60 years of age followed by 54 $(21.5 \%)$ patients with $41-50$ years of age group. Male: Female ratio was 1.2:1. The average stay of patients in the emergency department was $3.025 \pm 1.010$ days (Table 1 \& Figure 1).

Most common morbidity was cardiovascular disorders comprising 65 cases out of 250 followed by respiratory disorders comprising of 44 cases (Figure 2). Amongst cardiovascular diseases $(n=65)$, acute coronary syndrome was the most common diagnosis consisting about 15, followed by CHF consisting 13 patients.

\section{Drug utilization pattern}

A total of 250 patients received 2004 drugs, number of drugs prescribed per patient being $8.016 \pm 1.935$ (mean \pm standard deviation).

Using WHO drug prescription indicator, collected data were analyzed and found that average number of drugs prescribed per encounter was $8.016 \pm 1.935$, Percentage of encounter with antibiotics was $93.6 \%$, Percentage of encounters with injection was 97.6, Percentage of drugs prescribed by generic name was 18.86 , and Percentage of drugs from essential drug list was $52.14 \%$ (Table 2). 
The distribution of drugs among patients included in this study was: $30(7.5 \%)$ patients received five drugs; 20 $(5.98 \%)$ patients received six drugs; 60 (20.95\%) patients received seven drugs; $38(15.16 \%)$ patients received eight drugs; 58 (26.04\%) patients received nine drugs; 14(6.98) patients received ten drugs and the rest received more than ten drugs $30(17.36 \%)$. There were no patients who did not receive any drug.

The majority of drugs were administered in injectable form $1142(57 \%)$. Out of total number of drugs, i.e. 2004, $57 \%$ (1142) of the drugs are administered through injectable form and among injectable routes intra venous route is most frequently used contributing around $89 \%$ (1018) of total injectable (Table 5 \& Figure 3 ). It is rational to choose intravenous route in emergency department because we need faster and predictable action, which is provided by intravenous route. Injectables are followed by oral route contributing around $25 \%$ (506) of total routes. Inhalational route contribute around $18 \%$ (356) of total routes (Table 3 \& Figure 4).

Table 1: Demographic table showing age range and their frequency of distribution.

\begin{tabular}{|lcl|l|}
\hline $\begin{array}{l}\text { Age } \\
\text { Range }\end{array}$ & Frequency & $\begin{array}{l}\text { Sex wise } \\
\text { distribution of } \\
\text { frequency }\end{array}$ & Percentage \\
\hline $\mathbf{2 0}$ & 16 & $\begin{array}{l}\text { male=4 } \\
\text { female=12 }\end{array}$ & 6.4 \\
\hline $\mathbf{2 1 - 3 0}$ & 38 & $\begin{array}{l}\text { male=24 } \\
\text { female=14 }\end{array}$ & 15.2 \\
\hline $\mathbf{3 1 - 4 0}$ & 34 & $\begin{array}{l}\text { male=22 } \\
\text { female=12 }\end{array}$ & 13.6 \\
\hline $\mathbf{4 1 - 5 0}$ & 54 & $\begin{array}{l}\text { male=28 } \\
\text { female=26 }\end{array}$ & 21.6 \\
\hline $\mathbf{5 1 - 6 0}$ & 64 & $\begin{array}{l}\text { male }=38 \\
\text { female }=26\end{array}$ & 25.6 \\
\hline $\mathbf{6 1 - 7 0}$ & 32 & $\begin{array}{l}\text { male }=16 \\
\text { female }=16\end{array}$ & 12.8 \\
\hline $\mathbf{7 7 0}$ & 12 & $\begin{array}{l}\text { male=6 } \\
\text { female=6 }\end{array}$ & 4.8 \\
\hline
\end{tabular}

Table 2: Summary of results using W.H.O. prescription indicators.

\begin{tabular}{|ll|}
\hline Prescribing indicators assessed & Average/percent \\
\hline $\begin{array}{l}\text { Average number of drugs per } \\
\text { encounter }\end{array}$ & $8.016 \pm 1.935$ \\
\hline $\begin{array}{l}\text { Percentage of encounter with } \\
\text { antibiotics }\end{array}$ & $93.6 \%$ \\
\hline $\begin{array}{l}\text { Percentage of encounters with } \\
\text { injection }\end{array}$ & $97.6 \%$ \\
\hline $\begin{array}{l}\text { Percentage of drugs prescribed } \\
\text { by generic name }\end{array}$ & $18.86 \%$ \\
\hline $\begin{array}{l}\text { Percentage of drugs from } \\
\text { essential drug list }\end{array}$ & $52.14 \%$ \\
\hline
\end{tabular}

Table 3: Routes of drug administration and their frequency.

\begin{tabular}{|c|c|c|c|c|}
\hline $\begin{array}{l}\text { Routes of } \\
\text { drug } \\
\text { administrat } \\
\text { ion }\end{array}$ & Sub-class & $\begin{array}{l}\text { Freq } \\
\text { uenc } \\
\mathbf{y}\end{array}$ & Total & $\begin{array}{l}\text { Perce } \\
\text { ntage }\end{array}$ \\
\hline \multirow{3}{*}{ Injectables } & Intravenous & 1018 & \multirow{3}{*}{1142} & \multirow{3}{*}{$57 \%$} \\
\hline & Intramuscular & 98 & & \\
\hline & Sub cutaneous & 26 & & \\
\hline \multirow[t]{2}{*}{ Oral } & Solid form & 390 & \multirow[t]{2}{*}{506} & \multirow[t]{2}{*}{$25 \%$} \\
\hline & Liquid form & 116 & & \\
\hline Inhale & --- & 356 & 356 & $18 \%$ \\
\hline
\end{tabular}

Table 4: Various co morbid conditions identified.

\begin{tabular}{|llll|}
\hline S.N. & $\begin{array}{l}\text { Pathological } \\
\text { condition }\end{array}$ & $\begin{array}{l}\text { Number } \\
\text { of cases }\end{array}$ & Percentage \\
\hline $\mathbf{1}$ & Hypertension & 21 & 8.4 \\
\hline $\mathbf{2}$ & Tuberculosis & 17 & 6.8 \\
\hline $\mathbf{3}$ & COPD & 17 & 6.8 \\
\hline $\mathbf{4}$ & Diabetes mellitus & 15 & 6 \\
\hline $\mathbf{5}$ & $\begin{array}{l}\text { Chronic kidney } \\
\text { Disease }\end{array}$ & 14 & 5.6 \\
\hline $\mathbf{6}$ & Asthma & 14 & 5.6 \\
\hline $\mathbf{7}$ & $\begin{array}{l}\text { Coronary artery } \\
\text { Disease }\end{array}$ & 9 & 3.6 \\
\hline $\mathbf{8}$ & $\begin{array}{l}\text { Chronic liver } \\
\text { disease }\end{array}$ & 6 & 2.4 \\
\hline $\mathbf{9}$ & $\begin{array}{l}\text { Cerebrovascular } \\
\text { accident }\end{array}$ & 2 & 0.8 \\
\hline
\end{tabular}

Table 5: Table showing comparison between various studies.

\begin{tabular}{|c|c|c|c|c|}
\hline Name & $\begin{array}{l}\text { Ours } \\
\text { study }\end{array}$ & $\begin{array}{l}\text { Barot, } \\
\text { et } a l^{(8)} \\
(\mathbf{2 0 1 3})\end{array}$ & $\begin{array}{l}\text { Sharonje } \\
\text { et Kaur } \\
\text { et } a l^{(17)} \\
(2014)\end{array}$ & $\begin{array}{l}\text { Cheekav } \\
\text { olu C et } \\
\text { al }^{(9)} \\
(2011)\end{array}$ \\
\hline $\begin{array}{l}\text { Average } \\
\text { number of } \\
\text { drugs } \\
\text { prescribed }\end{array}$ & $\begin{array}{l}8.02 \pm \\
1.935\end{array}$ & $\begin{array}{l}9.99 \pm \\
2.55\end{array}$ & 4.9 & $4.2 \pm 1.2$ \\
\hline $\begin{array}{l}\text { Average } \\
\text { stay of } \\
\text { patient in } \\
\text { emergency } \\
\text { room }\end{array}$ & $\begin{array}{l}3.025 \\
\pm 1.01 \\
0 \text { days }\end{array}$ & 48 hours & $\begin{array}{l}2.23 \pm \\
1.3 \text { days. }\end{array}$ & 3 hours \\
\hline
\end{tabular}




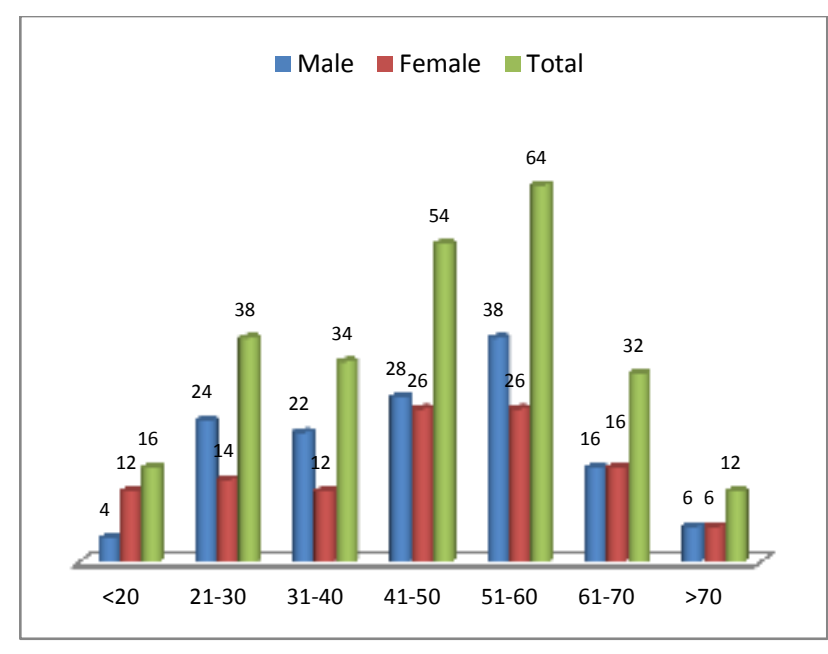

Figure 1: Age range and their frequency of distribution.

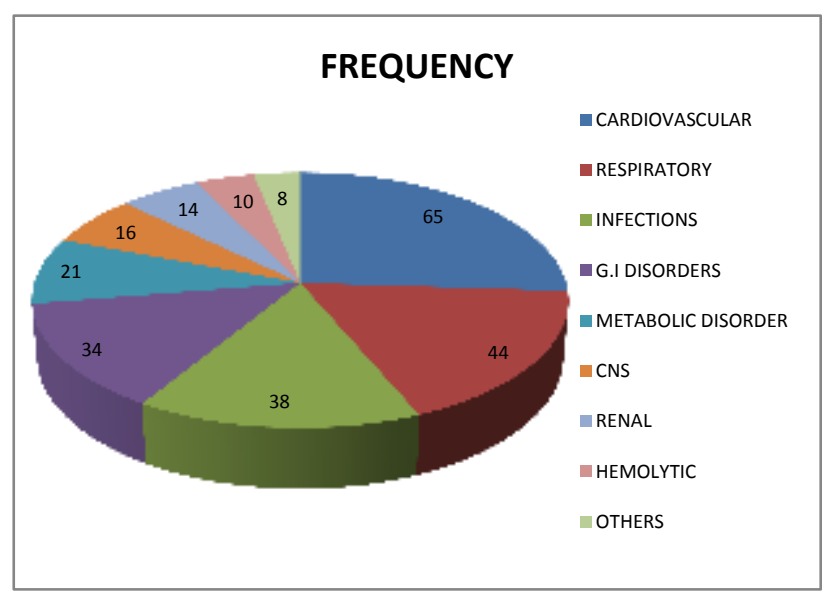

Figure 2: Common morbidity encountered in emergency medicine.

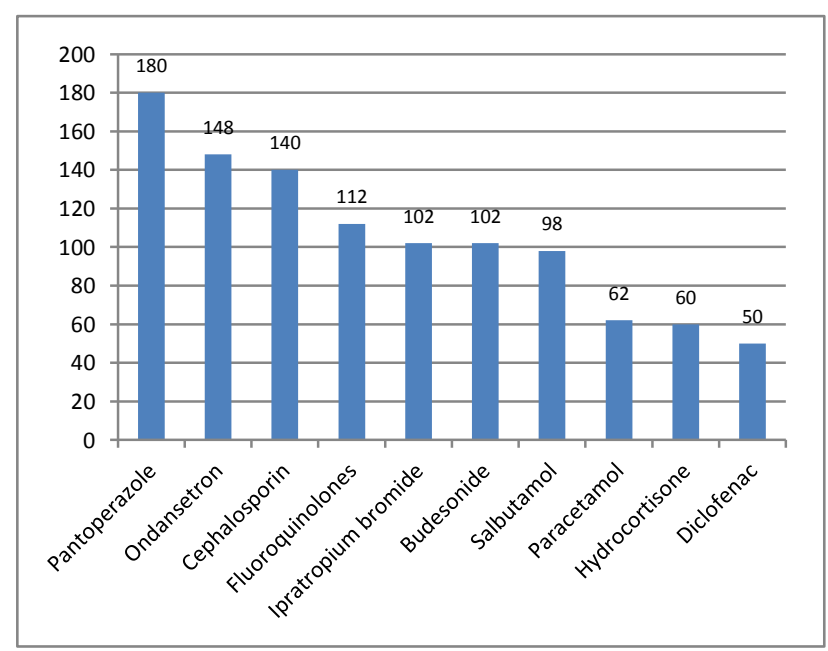

Figure 3: Top 10 most prescribed drugs.

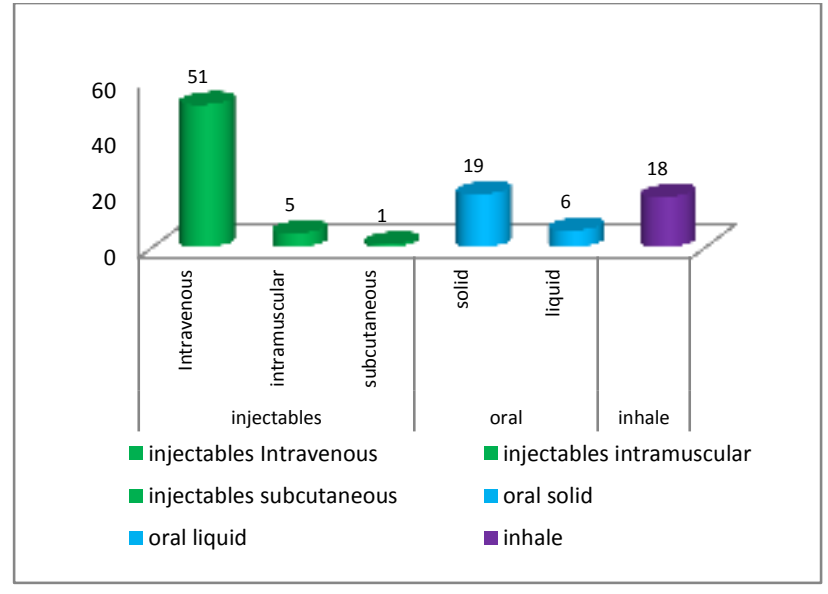

Figure 4: Routes of drug administration and their frequency.

\section{DISCUSSION}

The emergency department of a tertiary care unit of a developing country is faced with the problem of heavy patient load and relative paucity of human and economic resources. Specifically, our hospital is a premier tertiary care hospital which caters to a large population pool of the North Indian region. The drugs are prescribed by the attending internal medicine physician.

The average stay of the patients in the emergency was $3.025 \pm 1.010$ days. This indicates a rapid and efficient management of patients after which they were discharged or they were transferred to a medical ward.

Study on drug use in emergency medicine is important not only for the emergency physicians, but also for the general practitioners, who are often the first responders to emergencies in the middle and low income countries. ${ }^{7}$ In the present study, the drug use pattern in emergency medicine department for different clinical emergencies was studied for time period until patient stays in Emergency medicine department of TMMC \& RC.

In this study mean number of drugs per prescription, which is an important indicator of the standard of prescribing, was $8.02 \pm 1.935$. The reason for polypharmacy could be empirical therapy as the diagnosis may not be confirmed at the time of initial drug therapy. In another Indian study of prescribing in the emergency room, the mean number of drugs prescribed was $9.99 \pm 2.55 /$ prescription which supports to our study. ${ }^{8}$ In this study data were collected for initial 48 hours of treatment. One another study shows that average drugs prescribed was $4.2 \pm 1.2$ /prescription, which is in contrast to our study results. ${ }^{9}$ This difference could be due to the fact that the patients were followed only for the duration of initial $3 \mathrm{~h}$ of hospital stay in the previous study (Table $5)$. 
Among the cardiovascular disorders $(n=65)$, acute coronary syndrome was present in 15 individuals followed by congestive heart failure in 13 patients and arterial fibrillation was present in 11 patients, cardiogenic shock was present in 10 patients followed by pulmonary embolism $(n=10)$ and hypertensive emergency in 6 patients.

COPD $8 \%$ and asthma $6 \%$ was found more in patients of age group 51-60 years and patients belonging to rural areas rather than from urban areas. The association of ageing and respiratory problems is a result of cumulative effects of smoking and environmental exposure in susceptible individuals. Our study also found that patients from rural areas were chronic smokers; this might be the reason behind the higher number of patients of COPD and asthma. Moradabad area was found to be the thrust area for tuberculosis, because the population which lived in the villages had to come to the cities to earn their livelihood.

Various co morbid conditions were present in patients attending emergency medicine. Among 115 co morbid conditions, hypertension was primary diagnosis in $8.4 \%$ of total patients who were admitted in emergency medicine (Table 4). Hypertension is a powerful, independent, and modifiable risk factor behind the development of all major clinical manifestations of atherosclerotic cardiovascular diseases, which include coronary artery disease, stroke, peripheral artery disease, heart failure, renal failure, and dementia. ${ }^{10}$

It is necessary to keep mean number of drugs as low as possible to minimize the adverse effects, potential drugdrug interactions and to reduce the cost of treatment. About $81.14 \%$ of drugs were prescribed by brand name as compared with study of emergency room, in which $95 \%$ of drugs were prescribed by brand names. ${ }^{9}$ By using generic names of prescription chance of duplication of drug products is eliminated and cost to the patient decreases.

In our study, drugs acting on gastrointestinal (GI) tract, e.g. ondansetron and pantoprazole were most commonly prescribed empirically (Figure 3). Use of ondansetron is off-label as it is not approved anywhere for conditions other than chemotherapy or radiotherapy induced vomiting and post-operative nausea vomiting. ${ }^{11}$ Patanwala et al suggested that based on the comparative safety and efficacy of ondansetron with droperidol, promethazine, prochlorperazine, metoclopramide, ondansetron may be used as a first-line agent for relief of nausea or vomiting for most patient populations in the emergency department. $^{12}$

Physicians recommended pantoprazole a PPI as certain patients not receiving oral feeding or those receiving nonsteroidal anti-inflammatory drugs, aspirin and corticosteroid are supposedly at a high risk of developing gastric mucosal damage. The most frequently mentioned explanation for prescribing PPI without an indication was
"GI prophylaxis.” Jung and MacLaren suggested that PPIs are safe and efficacious for elevating intragastric $\mathrm{pH}$ in critically ill-patients for prevention of bleeding from stress-related mucosal damage. ${ }^{13}$ However, a study mentioned $\mathrm{H}_{2}$-receptor antagonists as appropriate initial agents, although PPIs have become first-line therapy in an increasing percentage of critical care patients, despite limited data regarding their use in this population. ${ }^{14}$

Majority of the patients were inappropriately prescribed ondansetron and pantoprazole without any approved indication, which was also reported by the earlier study. ${ }^{15}$

Approximately, $234(93.6 \%)$ of patients received antimicrobials. In an emergency setting, there is a dire need to give broad spectrum antibiotics as empirical therapy, which is essential is to narrow down the therapy as soon as we have a sensitivity report for the infecting organism. Overestimation of the severity of illness may be the main reason for such an empirical use of antimicrobials in emergency room. Antibiotics are among the most commonly prescribed drugs in hospitals and in developed countries around $30 \%$ of the hospitalized patients are treated with these drugs ${ }^{16}$ with the numbers much higher in developing countries. ${ }^{5}$

Out of total number of drugs, i.e. 2004, 57\% (1142) of the drugs are administered through injectable form and among injectable routes intra venous route is most frequently used contributing around 89\% (1018) of total injectables. It is rational to choose intravenous route in emergency department because we need faster and predictable action, which is provided by intravenous route.

\section{CONCLUSION}

Our analyzation of drug prescription pattern by using the WHO prescribing indicators in emergency medicine shows deviation from the standard recommended by W.H.O.

Hence, there is a need to bring changes in the prescribing practices with particular emphasis on generic drug prescribing and restricting polypharmacy.

Also, some amendments need to be incorporated in the hospital antibiotic policy. Besides, establishment of a system for provision of medicines at a subsidized rate to patients might prove a useful step towards decreasing costs of health care burden based on what the results revealed in this study, there is an inevitable need to improve prescription habits among different specialties.

This study concludes the need for rationalizing drug therapy in the emergency settings with regard to increasing adherence to national essential medicine list. Prescribing under generic name is considered economical and rational but in our study only $18.86 \%$ of the total drugs prescribed were under a generic name. Prescription 
under generic name should be increased to increase the rationality.

The result of this study highlights the importance of strategies that have to be implemented to optimize medication use at the emergency medicine department. antibiotics ( $n=406,20 \%)$ are among the most commonly prescribed drugs. The increasing prevalence of antimicrobial resistant pathogens has become well recognized over the past decade and is a matter of worldwide concern. Since the drug cost is mostly driven by prescription of broad spectrum antibiotics, therefore hospital pharmacy should be encouraged to procure more cost effective alternative antibiotics in future.

Our study has some limitations. We are not certain if our sample size of 250 patients was truly representative of total population visiting emergency medicine. Another limitation was that our study used the WHO prescribing indicators, which are supposed to record exactly what is prescribed to patients, but not why. The prescribing indicators measure aspects of outpatient treatment. They are designed for use in health centers, dispensaries or hospital outpatient departments. The prescribing indicators are less useful in specialty outpatient clinics in referral hospitals where the drug use pattern is more complex.

\section{ACKNOWLEDGEMENTS}

In particular, I would like to express my sincere appreciation and heartfelt gratitude to my esteemed teacher Dr. Farhan Ahmad Khan (Professor \& HOD) department of Pharmacology TMMC \& RC, TMU, Moradabad and my colleagues Mr. Subarna Bajracharya and Ataul Haque.

Funding: No funding sources

Conflict of interest: None declared

Ethical approval: The study was approved by the Institutional Ethics Committee

\section{REFERENCES}

1. Ehijie FO, Enato, Chima IE. Evaluation of drug utilization patterns and patient care practices. West Afr J PharM. 2011;22(1):36-41.

2. Jimoh AO, Etuk EU, Sani Z, Shuaibu HA. The pattern of antibiotic use in a family medicine department of a tertiary hospital in Sokoto, north western Nigeria. J Clin Diag Res. 2011;5(3):566-9.

3. Teferra A, Zeruesenay D, Asfawossen GY. Prescribing pattern of drugs in medical wards of three hospitals in north-west Ethiopia. J Ethiopia Med Pract. 2002;4:8-1.

4. Erah PO, Olumide GO, Okhamafe AO. Prescribing practices in two health care facilities in Warri, Southern Nigeria: A comparative study. Trop J Pharm Res. 2003;2(1):175-82.
5. Rehana HS, Nagarani MA, Rehan MA. Study on the drug prescribing pattern and use of antimicrobial agents at tertiary care teaching hospital in eastern Nepal. Indian J Pharmacol. 1998;30:175-80.

6. Akhtar MS, Divya V, Pillai K, Kiran D, Roy MS, Najmi AK et al. Drug prescribing practices in pediatric department of a north Indian university teaching hospital. Asian J Pharm Clin Res. 2012;5:146-9.

7. David S. Textbook of emergency medicine. $1^{\text {st }}$ edition. India: Lippincott Williams and Wilkins; 2011: 1155-1156.

8. Barot PA, Malhotra SD, Rana DA, Patel VJ, Patel KP. Drug utilization in emergency medicine department at a tertiary care teaching hospital: A prospective study. J Basic Clin Pharm. 2013;4:7881.

9. Cheekavolu C, Pathapati RM, Babasaheb Laxmansingh K, Saginela SK, Makineedi VP, Siddalingappa et al. Evaluation of drug utilization patterns during initial treatment in the emergency room: A retro prospective pharmacoepidemiological study. ISRN Pharmacol. 2011;2011:261585.

10. Reaven GM. Insulin resistance, hyper-insulinaemia and hypertriglyceridaemia in the etiology and the clinical course of hypertension. Am $\mathbf{J}$ Med. 1991;90:7s-12s.

11. Longo DL, Fauci AS, Kasper DL, Hauser SL, Jameson JL, Loscalzo J. Harrison's Principles of Internal Medicine. $18^{\text {th }}$ edition .USA: McGraw-Hill Companies; 2012: 247.

12. Patanwala AE, Amini R, Hays DP, Rosen $P$. Antiemetic therapy for nausea and vomiting in the emergency department. J Emerg Med. 2010;39:3306.

13. Jung R, MacLaren R. Proton-pump inhibitors for stress ulcer prophylaxis in critically ill patients. Ann Pharmacother. 2002;36:1929-37.

14. Daley RJ, Rebuck JA, Welage LS, Rogers FB. Prevention of stress ulceration: current trends in critical care. Crit Care Med. 2004;32:2008-13.

15. Lat I, Micek S, Janzen J, Cohen H, Olsen K, Haas C. Off-label medication use in adult critical care patients. J Crit Care. 2011;26:89-94.

16. Shankar RP, Partha P, Shenoy NK, Easow JM, Brahmadathan KN. Prescribing patterns of antibiotics and sensitivity patterns of common micro-organisms in the internal medicine ward of a tertiary hospital in Western Nepal: a prospective study. Ann Clin Microb Antimicrob. 2003;2:1-9.

17. Kaur S, Rajagopalan S, Kaur N, Shafiq N, Bhalla A, Pandhi P, Malhotra S. Drug utilization study in medical emergency unit of a tertiary care hospital in North India. Emerg Med Int. 2014; 2014:973578.

Cite this article as: Pandey K, Khan IA. Drug prescribing patterns in patients visiting the emergency medicine department at a tertiary care teaching hospital: a prospective study. Int J Basic Clin Pharmacol 2016;5:163-8. 